\title{
MINDFULNESS AND GENDER: A PILOT QUANTITATIVE STUDY
}

\author{
Wenli Wang, Robert Morris University, wangw@rmu.edu \\ Tenzin Chopel, Land of Compassion Buddha, choepel_tenzin@yahoo.com
}

\begin{abstract}
Mindfulness is often referred to as a receptive state of mind in which attention simply observes what is taking place at the present moment. Mindfulness research has flourished in the fields such as neuroscience and psychology, yet, it still lacks in the field of information systems (IS), especially with quantitative studies. This research conducted a pilot quantitative study that uses the Mindful Attention Awareness Scale (MAAS) (Brown \& Ryan, 2003) to measure the mindfulness disposition among IS college students. It also examines the role of gender in mindfulness disposition. The results show that the IS college students' mindfulness dispositions are satisfactory. Female students have a wider variance in mindfulness dispositions than male students. In addition, it was unexpectedly observed that the subjective survey results corresponded to the objective mindful/non-mindful behavior of the survey subjects.
\end{abstract}

Keywords: Mindfulness, Contemplative Studies, Gender, MAAS, Information Systems

\section{INTRODUCTION}

Mindfulness is often referred to as "a receptive state of mind in which attention, informed by a sensitive awareness of what is occurring in the present, simply observes what is taking place" (Brown \& Ryan, 2003). The benefits of mindfulness have been scientifically proven in a relatively new field called Contemplative Studies, with its initial popularity among neuroscientists, psychologists and religious leaders, and the subsequent interests from educators (e.g., Association for Contemplative Mind in Higher Education), business academicians (e.g., Academy of Management), and industrial professionals (e.g., Google, Wisdom 2.0 community).

Contemplative Studies is a rising scientific and educational discipline. Mindfulness-based interventions (Kabat-Zinn, 1990; Segal et al. 2002) have been proven to be valid therapy treatments for psychological problems such as depression or addiction. Yet, mindfulness research in information systems (IS) is still lacking, despite the rising phenomena of technology-induced stress and addiction and the IS industry's recognition of applying mindfulness training to address these issues (Wang, 2015). In addition, it is important to study how to promote mindfulness in IS workforce because they play a critical role in designing and implementing IS infrastructure and capabilities for the society (Wang, 2015). There are limited conceptual or qualitative studies on mindfulness in IS. The conceptual studies mainly focus on the application of mindfulness in the IS development processes, especially in information technology innovation (Mu \& Bulter, 2009; Ramiller \& Swanson, 2009; Surendra, 2009; Swanson \& Ramiller, 2004), agile development (Vidgen \& Wang, 2009), team management (Alnuaimi, Robert, \& Maruping, 2010; Dabbish \& Kraut, 2008) and reliability (Butler \& Gary, 2006; Carlo, Lyytinen, \& Boland, 2012). Wang $(2015,2017)$ have conducted qualitative case studies regarding mindfulness in IS and extended the application of mindfulness from IS development processes to end-user experiences. These qualitative studies mainly extended the definitions of mindfulness from the contemporary western research to the traditional Buddhism understandings.

However, there is no quantitative studies yet on mindfulness in IS. This research aims to fill in such a gap in the literature by piloting a quantitative study. Specifically, this research is interested in the quantitative measure of mindfulness disposition among IS college students and the approach to improve their mindfulness dispositions.

Katz \& Toner (2013) conducted a meta-study of the gender differences in the effectiveness of mindfulness-based treatments for substance use disorders and recommend that additional research is needed to include gender as a construct. Following such a recommendation, this research also studies the role of gender in relation to mindfulness disposition. Hence, the study asks the following four research questions: 
RQ1: What is the mindfulness disposition of the college students in information systems?

RQ2: Does the mindfulness disposition differ in gender?

RQ3: Does the introduction of mindfulness positively affect one's mindfulness disposition?

RQ4: Does gender moderate the relationship between the introduction of mindfulness and the change in one's mindfulness disposition?

This paper is organized as follows: Section II provides the literature review on mindfulness. Section III discusses the quantitative research method used in this study. Section IV shows the results of the pilot quantitative study. Section $\mathrm{V}$ further discusses the results and their implications to the practices and the future research. Section VI concludes.

\section{LITERATURE REVIEW}

\section{Mindfulness and IS}

The detailed literature review on mindfulness in IS, especially in the IS development processes, can be found in Wang $(2015,2017)$. Built on the existing literature, Wang $(2015,2017)$ examined the definitions of mindfulness and their applications in the context of systems design and technology user experience. These two studies expand the contemporary definition in the western literature to include the traditional definition of mindfulness in the eastern Buddhism. They also examine these definitions in the systems analysis and design, especially for promoting the mindful technology user experience with the proactive systems design.

Wang (2015) showed that IS students were open to concepts from both the IS literature and Buddhism, and were able to understand and apply the diverse interpretations of mindfulness in the IS design process and in systems outcome. Overall, the majority of the IS students who were exposed to mindfulness during the class have recognized its importance in IS design and have suggested approaches geared toward reaching a system outcome that promotes mindful user experience of the system, as well as reporting that they themselves are also incorporating mindfulness into their daily attitudes and behaviors. Wang (2017) found that, even without the explicit exposure to the literature, more than half of the IS students can interpret mindfulness using both the concepts in the existing IS literature and in Buddhism. For those students who have not related to both, they applied the IS literature to interpret mindfulness in systems development and applied Buddhism to interpret mindfulness in end user experience.

Both qualitative studies showed that the introduction of mindfulness in systems courses has affected students' mindfulness. In Wang (2015), the instructor introduced much more in details of the mindfulness definitions in the contemporary IS literature and in the traditional Buddhism to the students and provided examples to guide the students in the systems course. However, Wang (2017) did not provide such details and let the students self-learn and explore on their own as a challenge and an exercise for students to gather systems requirement information from the stakeholders. It turned out that IS students were quite proficient in the self-learning and the application of new concepts such as mindfulness. Different from Wang $(2015,2017)$, this research continue examining if the introduction of mindfulness affects students' mindfulness disposition but with a quantitative rather than qualitative measure.

\section{Mindfulness Measurement}

The Mindfulness Attention Awareness Scale (MAAS) (Brown \& Ryan, 2003) was the chosen measurement for the construct mindfulness. The MAAS is designed to assess mindfulness, namely, "a receptive state of mind in which attention, informed by a sensitive awareness of what is occurring in the present, simply observes what is taking place" (Brown \& Ryan, 2003). Brown and Ryan (2003) also stated that through "correlational, quasi-experimental, and experimental studies that the trait MAAS taps a unique quality of consciousness that is related to, and predictive of, a variety of emotion regulation, behavior regulation, interpersonal, and well-being phenomena." The MAAS scale was selected to measure mindfulness and to further examine if mindfulness can serve as a predictive construct for the behavioral regulation related to IS. 
Other relevant alternative measurement scales were examined, such as the Schutte Self Report Emotional Intelligence Test (SSEIT) scale (Schutte et al., 1998). The MAAS scale was chosen due to its fit with this research, its reliability and validity (Brown \& Ryan, 2003), and the efficiency. The MAAS scale is a fifteen-item scale. This measurement of mindfulness only takes five minutes or less to complete. Such a short and not time-consuming scale is suitable to be issued in a classroom of the educational setting. Please see the questions in the MAAS scale in the Appendix A. The higher average score of all the question, the higher levels of dispositional mindfulness.

\section{RESEARCH METHODOLOGY}

A pilot quantitative study was conducted. The questionnaire of MAAS was issued to the students in a systems analysis and design course at the beginning and the end of the course and before and after a course project related to mindfulness. A qualitative study with self-reflection on mindfulness and systems was also conducted. However, the qualitative study and its results are not discussed or analyzed here in this paper due to the page limit constraints.

In order to indirectly introduce the concepts of mindfulness, a course project was introduced to focus on designing interactive websites for a mindfulness related organizations. The students were asked to conduct systems analysis and design for a fictitious non-profit organization that promotes mindfulness education and practices in international communities of practices.

Since it was an eight-week graduate course where the class met once a week in the evening, it was crucial to have an early start of the semester-long course project. Therefore, after the introduction of the course syllabus and a brief overview of the course content at the first class meeting, the semester-long course project was immediately introduced. A handout about the fictitious mindfulness organization was given to the students where the content mainly focused on the organizational structures and the need for information systems. The concepts of mindfulness were only introduced but not delved upon in detail. It is the instructor's intention to have the students to self-explore mindfulness as part of the exercise for systems analysis and design requirements solicitation.

The course project asked the students to design and implement the main and subsidiary websites for the mindfulness organization. It imitates a real-world organization where different departments need to collaborate to support the organization and the main website needs to at least offers a place to host the subsidiary websites, if not to instruct and govern the other subsidiaries. The purpose to have the course project with the common goal of supporting one organization but with the different websites to be designed allowed the students in different groups to partially serve as the stakeholders and reviewers for other groups. The details of the course project can be found in Wang (2015) where the content of the main and subsidiary websites were discussed.

During the first half of the first class meeting, not only was the course project introduced and discussed but students were also asked to introduce themselves to the class as well as indicate their technical and business background related to systems analysis and design. The students then were asked to form groups. In the second half of the class, students selected their group members. The instructor helped the adjustment when necessary and made the final decision.

The questionnaires of MAAS was given to the student right after the course project was introduced and the groups were assigned. This pre-project survey was to obtain the initial baseline of the student's mindfulness disposition. The students had the choice whether or not to take the survey and were given the option to be anonymous or to provide the identity. In order to match and pair the pre-project and post-project surveys, it was suggested to the students who do not provide names to make a special mark on the pre-project survey and use the same make in the post-project survey.

\section{RESULTS}

There were seventeen (17) students in the systems analysis and design course. Among them, seven (7) were female students and ten (10) were male students. Two (2) male students joined the class late and they did not answer the preproject survey. Therefore, these two subjects' responses were not used. The remaining fifteen (15) students answered 


\section{Issues in Information Systems}

Volume 18, Issue 4, pp. 105-115, 2017

both the pre- and post-project surveys. Among them, only two (2) subjects are anonymous and all other thirteen (13) subjects volunteered to provide their identities.

Since this was a graduate level course, there were about $40 \%$ of female students and $60 \%$ of male students enrolled in class. If this were an undergraduate course, the percentage of female students would have been lower. For the valid data points, $53 \%$ were from male subjects and $47 \%$ were from the female subjects. Table 1 shows the demographics statistics. The sample size of 15 is small. It does not satisfy the requirement for a statistically significant quantitative study where the results are generalizable to a large population. This pilot quantitative study only aims to provide some baseline information for a future quantitative research that leads to generalizable results. Similar to Wang (2015, 2017), a second survey with three qualitative essay questions was also issued to the students at the same time when the post-project quantitative survey was issued. 13 out of 17 students provided their qualitative feedback. A future study will combine and cross-examine the results from both the quantitative and qualitative analysis.

Table 1. Survey Demographics

\begin{tabular}{|l|c|c|}
\hline Total & Male & Female \\
\hline $\mathrm{N}=15$ & 8 & 7 \\
\hline $100 \%$ & $53 \%$ & $47 \%$ \\
\hline
\end{tabular}

There were only two missing data points in the pre-project survey among 225 total data points. However, there were four students who forgot to answer the last four questions in the MAAS survey (i.e., 16 missing data points the postproject survey). These missing data points were due to three reasons: 1) The last four questions in the MAAS survey were on the second page; 2) The researcher may have reminded the students to notice the second page in the firstround of survey, however, the researcher may have assumed that the students would have remembered to answer the questions on the second page; and 3) The post-project survey was conducted after the semester-long course project was finished and presented and right before the final exam. Students may have experienced high-level of stress during the project completion and final exam periods and this high stress level may have caused relatively non-mindful behavior, which is demonstrated in the missing data points. These 16 missing data points were replaced with the subjects' corresponding scores in the pre-project survey. Similarly, the 2 missing data points were replaced with the same subjects' corresponding scores in the post-project survey.

The data analysis are shown below to help answer the four research questions. Note that the MAAS scores range from 1-6 where the score of 1 indicates one "almost always" has non-mindful behaviors the score of 6 indicates one "almost never" has non-mindful behaviors (see Appendix A).

\section{RQ1. What is the mindfulness disposition for students in information systems?}

Table 2. Mindfulness Disposition

\begin{tabular}{|c|c|c|c|c|}
\hline $\mathrm{N}=15$ & Mean & Std. & Min. & Max. \\
\hline Average & $\mathbf{4 . 5 2}$ & 1.05 & 3.47 & 5.93 \\
\hline
\end{tabular}

Table 2 shows that the average mindfulness score of 4.52 shows that the surveyed subjects have a relatively good dispositional mindfulness - it fall right in between 4-"somewhat infrequently" and 5 - "very infrequently" nonmindful behavior. Even the minimum score of mindfulness $(=3.47$ out of 6$)$ fall in the middle of 3 -"somewhat frequent" and 4 - "somewhat infrequently" non-mindful behavior. And the maximum score of mindfulness (=5.93) is very close to the full mark of 6 . These results show that the mindfulness disposition among IS students is overall satisfying.

\section{RQ2: Does the mindfulness disposition differ in gender?}

Table 3. Mindfulness Disposition by Gender

\begin{tabular}{|c|c|c|c|c|c|c|c|c|}
\hline Total (N=15) & \multicolumn{4}{|c|}{ Male $(\mathrm{n}=8)$} & \multicolumn{4}{c|}{ Female (n=7) } \\
\hline Statistics & Mean & Std. & Min. & Max. & Mean & Std. & Min. & Max. \\
\hline Average & $\mathbf{4 . 4 6}$ & $\mathbf{0 . 9 4}$ & - & - & $\mathbf{4 . 5 9}$ & $\mathbf{1 . 2}$ & - & - \\
\hline
\end{tabular}


Table 3 shows that there are not much difference in the average mindfulness score between male and female. The average male score is 4.46 and the average female score is 4.59 . However, there are some differences in the variances by gender. The average standard deviation among male subjects is 0.94 whereas the average standard deviation among female subjects is 1.2. This implies that the female's disposition mindfulness varies more than that of male.

\section{RQ3: Does the introduction of mindfulness concept increase one's mindfulness?}

Table 4 shows that there is almost no change in mindfulness disposition pre- and post-intervention where the intervention was to introduce the concept of mindfulness to the students and to have the students work on a semesterlong course project related to mindfulness. It is assumed that students further self-study and explore the concept of mindfulness and at the same time build up their disposition of mindfulness. However, the result shows that there is actually a slight decrease in mindfulness with the average mindfulness score of 4.55 pre-intervention and that of 4.48 post-intervention. The variances in the two time periods remain almost the same.

Table 4. Mindfulness Disposition by Time (pre- and post- mindfulness-intervention)

\begin{tabular}{|c|c|c|c|c|}
\hline $\mathrm{N}=15$ & Mean & Std. & Min. & Max. \\
\hline $\begin{array}{c}\text { Mindfulness (Time 1) } \\
\text { (pre-intervention) }\end{array}$ & 4.55 & 1.04 & 3.47 & 5.93 \\
\hline $\begin{array}{c}\text { Mindfulness (Time 2) } \\
\text { (post-intervention) }\end{array}$ & 4.48 & 1.06 & 3.47 & 5.73 \\
\hline Average & $\mathbf{4 . 5 2}$ & 1.05 & 3.47 & 5.83 \\
\hline
\end{tabular}

\section{RQ4: Does gender moderate the increase in one's mindfulness with the introduction of mindfulness concept?}

Table 5 shows that gender does play a role in the change of one's mindfulness disposition with the introduction of mindfulness concept. Surprising the gender effects differ in two directions. Male subjects increase their mindfulness disposition from an average score of 4.33 pre-intervention to that of 4.59 post-intervention. In contrast, the female subjects decrease their mindfulness disposition from an average score of 4.78 pre-intervention to that of 4.39 postintervention.

Table 5. Mindfulness Disposition by Gender and Time (pre- and post- mindfulness-intervention)

\begin{tabular}{|c|c|c|c|c|c|c|c|c|}
\hline Total (N=15) & \multicolumn{4}{|c|}{ Male (n=8) } & \multicolumn{4}{c|}{ Female (n=7) } \\
\hline Statistics & Mean & Std. & Min. & Max. & Mean & Std. & Min. & Max. \\
\hline $\begin{array}{c}\text { Mindfulness Time 1 } \\
\text { (pre-mindfulness project) }\end{array}$ & $\mathbf{4 . 3 3}$ & $\mathbf{0 . 9 2}$ & 3.47 & 5.93 & $\mathbf{4 . 7 8}$ & $\mathbf{1 . 2}$ & 4.47 & 5.27 \\
\hline $\begin{array}{c}\text { Mindfulness Time 2 } \\
\text { (post-mindfulness project) }\end{array}$ & $\mathbf{4 . 5 9}$ & $\mathbf{0 . 9 6}$ & 3.47 & 5.73 & $\mathbf{4 . 3 9}$ & $\mathbf{1 . 2}$ & 3.73 & 5.47 \\
\hline Average & $\mathbf{4 . 4 6}$ & $\mathbf{0 . 9 4}$ & - & - & $\mathbf{4 . 5 9}$ & $\mathbf{1 . 2}$ & - & - \\
\hline
\end{tabular}

The female subjects overall have a higher mindfulness disposition than male subjects both in the pre-intervention baseline (average score of 4.78 in female vs. that of 4.33 in male) and in the overall average score for both the time periods (4.59 in female vs 4.46 in male).

The female subjects have higher variances in their mindfulness dispositions than the variances in the male subjects. And these variances remain almost the same despite the differences in the average mindfulness scores in female vs. male. The variances in both time periods in female were 1.2 vs. those in male were 0.92 and 0.96 . This widened variance in female may indicate the wider spread of mindfulness disposition in female than that in male.

However, the minimum and maximum scores in female and male tell the different story. In both time periods of preand post-intervention of the mindfulness project, the male subjects have the lower minimum (3.47/3.47 in male vs. 4.47/3.73 in female) and higher maximum (5.93/5.73 in male vs. 5.27/5.47 in female) mindfulness scores. The wider spread between minimum and maximum scores in male indicate that there are more extremes cases in male subjects when they respond the survey. However, the widened variance in female responses indicate that female's mindfulness 
dispositions are clustered together around the average scores and yet their individual scores vary much inside the cluster.

\section{A Post hoc Observation:}

It was interesting that the female mindfulness score actually decreased after the exposure to the mindfulness concept. Was the decrease due to the subjectivity in the survey responses? Or the decrease also corresponds to the observable objective mindful/non-mindful behavior? An unexpected post hoc observation leads to a surprising result: it happened that the subjective survey results in MAAS corresponded to the observable objective mindful behavior of the survey subjects. Table 6 indicates that the decrease in female's mindfulness disposition actually corresponds to the observable objective non-mindful behavior. The MAAS survey instrument was split into two pages, which provides an organic setting to observe the respondents' objective mindful/non-mindful behavior. Those who have finished all the questions, without the reminder from the researcher, have demonstrated objective mindful behavior; those without answering all the questions, such as those who did not mindfully notice that there are additional four questions in the second page or forgot that they have answered the pre- survey in two pages, have demonstrated objective non-mindful behavior.

One may argue that it is not uncommon that some students simply do not finish answering all questions in a survey. They may skip questions or abandon the survey completely in midway. Although it is difficult to interpret such a behavior of missing answering the second-page questions as lack of mindfulness with certainty, the difference in missing data in the pre- and post-project surveys does provide some interesting observations and insight.

Table 6. Non-mindful Behavior by Gender and Time (pre- and post- mindfulness-intervention)

\begin{tabular}{|c|c|c|c|c|c|c|}
\hline Time & $\begin{array}{c}\text { Total } \\
(\mathrm{N}=15)\end{array}$ & $\begin{array}{c}\text { Male } \\
(\mathrm{n}=8)\end{array}$ & $\begin{array}{c}\text { Female } \\
(\mathrm{n}=7)\end{array}$ & $\begin{array}{c}\text { Total } \\
\text { missing data } \\
\text { (total 225 } \\
\text { data points) }\end{array}$ & $\begin{array}{c}\text { Missing data } \\
\text { from Male } \\
\text { (total 120 male } \\
\text { data points) }\end{array}$ & $\begin{array}{c}\text { Missing data } \\
\text { from female } \\
\text { (total 105 female } \\
\text { data points) }\end{array}$ \\
\hline $\begin{array}{c}\text { Non-mindful behavior T1 } \\
\text { indicated w/ missing data } \\
\text { (pre-mindfulness project) }\end{array}$ & $\begin{array}{c}2 \\
(13.3 \%)\end{array}$ & $\begin{array}{c}1 \\
(12.5 \%)\end{array}$ & $\begin{array}{c}1 \\
(14.3 \%)\end{array}$ & $\begin{array}{c}2 \\
(0.88 \%)\end{array}$ & $\begin{array}{c}1 \\
(0.83 \%)\end{array}$ & $\begin{array}{c}1 \\
(0.95 \%)\end{array}$ \\
\hline $\begin{array}{c}\text { Non-mindful behavior T2 } \\
\text { indicated w/ missing data } \\
\text { (post-mindfulness project) }\end{array}$ & $\begin{array}{c}4 \\
(26.6 \%)\end{array}$ & $\begin{array}{c}1 \\
(12.5 \%)\end{array}$ & $\begin{array}{c}\mathbf{3} \\
\mathbf{( 4 2 . 8 \% )}\end{array}$ & $\begin{array}{c}16 \\
(7.1 \%)\end{array}$ & $\begin{array}{c}4 \\
(3.3 \%)\end{array}$ & $\mathbf{1 2}$ \\
\hline
\end{tabular}

Altogether for both genders, $13.3 \%$ of the survey subjects demonstrated non-mindful behavior in the pre-survey with two missing data points $(0.88 \%$ of total data points) and $26.6 \%$ of the survey subjects demonstrated non-mindful behavior in the post-survey with sixteen missing data points ( $7.1 \%$ of total data points).

The male subjects' objective mindful/non-mindful behaviors have less variance during the two time periods than those of the female subjects. Only one out of eight male subjects $(12.5 \%)$ missed one data input $(0.83 \%$ of total male data points) in the pre-intervention survey. Almost consistently, it was still one out of eight male subjects $(12.5 \%)$ missed four data inputs (3.3\% of total male data points) in the post-intervention survey.

However, the female subjects' objective mindful/non-mindful behaviors vary greatly. Similar to the male counterpart, only one female subject (out of seven, which makes it $14.3 \%)$ missed one data point $(0.95 \%$ of total female data points) in the pre-intervention survey. But, in the post-intervention survey, three female subjects (out of seven, which makes it $42.8 \%$ ) missed twelve data points ( $11.4 \%$ of total female data points).

Interestingly, three out of four subjects who forgot to answer the four questions in the post-project survey were females - that is about $43 \%$ of female subjects (vs. $12.5 \%$ of male). This increased high percentage (almost $200 \%$ jump from the pre-intervention time) of the female subjects' having non-mindful behavior echo with the subjective survey results that the average mindfulness score among female students actually decreased in the post-intervention time. 


\section{Issues in Information Systems}

Volume 18, Issue 4, pp. 105-115, 2017

\section{DISCUSSIONS}

It had been hypothesized in research question \#3 that the introduction of the mindfulness concept would have increased one's mindfulness disposition. However, the result is inconclusive. For male subjects, it was true; however, the female subjects actually decrease their mindfulness. One possible explanation is that mindfulness disposition tightly relates to one's stress level, despite the introduction or even the in-depth study of the mindfulness concept.

There is plenty of literature showing the positive effects of mindfulness in stress-reduction. The connection of stress and mindfulness are in two-ways. High stress may also reduce one's mindfulness. The post-project time is also the high stress time for the students where they just finished the complicated course project and project presentation and what is ahead of them is the final exam. Naturally they are highly stressed, which may affect their dispositions of mindfulness. Hence, it is suggested from this research that the level of stress is most likely a confounding factor in the relationship between mindfulness study and mindfulness disposition. Future research should contemplate on how to manage and control the effect of this confounding factor in the examined relationship. Without controlling this confounding factor, it is inconclusive whether or not the introduction of mindfulness concept increase one's mindfulness disposition.

The differences by gender in the change in the mindfulness disposition may indicate that female could be more susceptible to the change of stress levels than male. Hence, the future research needs to take into account of the moderation effects of gender and the interactions between gender and stress levels.

In addition, the level of exposure to the mindfulness concept and study is not well controlled in this pilot study. Due to the fact that this course is a systems analysis and design course, rather than a philosophy or religious course on mindfulness, the instructor only indirectly introduces the concept of mindfulness in a course project. Limited time was devoted in the topic of mindfulness and it is uncertain how much in-depth students were exploring mindfulness. The instructor provided feedback mostly on the knowledge subjects of systems analysis and design rather than on the subject of mindfulness. There is no other formal assignment or examination on mindfulness, through which the instructor can control the level of exposure to this concept to all the students. How to control and measure different levels of exposure to mindfulness concept is another consideration in the future research.

As a matter of fact, it was not in the original design but a coincident for examining the relationship between the subjective survey responses and the objective mindful/non-mindful behavior related to the survey. It just happened that the original MAAS survey was split into two pages, which provides an organic setting to observe the respondents' objective mindful/non-mindful behavior. This accidental setting can be further intentionally explored and additional such settings can be embedded to objective measure about mindful/non-mindful behavior of the survey subjects, supplementing and matching with the subjective survey results.

Due to the limited sample size and the fact that this research was only a pilot study, no inferential statistics were conducted. Only descriptive statistics were examined in the data analysis. Future study would refine the research model, increase the sample size, refine the measurement(s) and hope to provide generalizable results from the study on the sample.

The study design and methodology are not necessarily specific to the IS discipline - the MAAS measure could be administered to any group of students regardless of their field of study. Future study could involve students in other fields of study.

\section{CONCLUSIONS}

This research conducted a pilot quantitative study to fill in the research gap of lacking quantitative studies of mindfulness in information systems research. It applies a course project related to mindfulness systems analysis and design as an intervention to study the pre- and post- mindfulness dispositions in college IS students and the role of gender. Although the sample size was small, the results were interesting. The college students in information systems have a satisfying mindfulness disposition based on the measure of MAAS scale. 


\section{Issues in Information Systems}

Volume 18, Issue 4, pp. 105-115, 2017

Male and female students do not vary significantly in their average mindfulness dispositions overall, however, the female students have a wider variance in mindfulness dispositions than the male students. Although the female students' mindfulness dispositions are higher than those of the male students in the pre-intervention, the male students' mindfulness dispositions actually increased after they were exposed to the concept of mindfulness. On the contrary, the female students' mindfulness dispositions decreased post hoc.

An unexpected finding is that such a decrease in mindfulness among females corresponded to their observable objective non-mindful behavior (e.g., survey questions on the second page of the survey were left unanswered by more female students than male). A possible explanation is that the post-intervention survey was issued during the highstress time (e.g., the ending time for the course project and the coming of the final exam) and females may be more susceptible to stress. Future research needs to consider the control of potential confounding factors such as stress and to increase the sample size that helps render more generalizable results.

\section{REFERENCES}

Alnuaimi, O. A., Robert, L. P., \& Maruping, L. M. (2010). Team size, dispersion, and social loafing in technologysupported teams: a perspective on the theory of moral disengagement. Journal of Management Information Systems, 27(1), 203-230.

Brown, K.W., \& Ryan, R.M. (2003). The benefits of being present: mindfulness and its role in psychological wellbeing. Journal of Personality and Social Psychology, 84, 822-848.

Butler, B. S., \& Gray, P. H. (2006). Reliability, mindfulness, and information systems. MIS Quarterly, 30(2), 211224.

Carlo, J. L., Lyytinen, K., \& Boland, R. J. (2012). Dialectics of collective minding: contradictory appropriations of information technology in a high-risk project. MIS Quarterly, 36(4), 1081-1108.

Dabbish, L., \& Kraut, R. (2008). Awareness displays and social motivation for coordinating communication. Information Systems Research, 19(2), 221-238.

Kabat-Zinn, J. (1990). Full catastrophe living: using the wisdom of your body and mind to face stress, pain and illness, New York: Hyperion.

Katz, D., \& Toner, B. (2013). A systematic review of gender differences in the effectiveness of mindfulness-based treatments for substance use disorders. Mindfulness, 4(4), 318-331.

Mu, E., \& Butler, B. S. (2009). The assessment of mindfulness processes for the effective assimilation of IT innovation. Journal of Decision Systems, 18(1), 27-51.

Ramiller, N. C., \& Swanson, E. B. (2009). Mindfulness routines for innovating with information technology. Journal of Design Systems, 18, 13-26.

Schutte, N. S., Malouff, J. M., Hall, L. E., Haggerty, D. J., Cooper, J. T., Golden, C. J., \& Dornheim, L. (1998). Development and validation of a measure of emotional intelligence. Personality and Individual Differences, 25, 167-177.

Segal, Z., Williams, J., \& Teasdale, J. (2002). Mindfulness based cognitive therapy for depression, New York: Guilford.

Surendra, N.C. (2009). Agile development as an enabler of mindful IT innovation adoption - lessons from an action research project .Journal of Design Systems, 19, 99-115. 


\section{Issues in Information Systems}

Volume 18, Issue 4, pp. 105-115, 2017

Swanson, E. B., \& Ramiller, N. C. (2004). Innovating mindfully with information technology. MIS Quarterly, 28(4), 553-583.

Vidgen, R., \& Wang, X. F. (2009). Coevolving systems and the organization of agile software development. Information Systems Research, 20(3), 355-376.

Wang, W. (2015). Building a contemplative IS workforce through promoting mindfulness in IS design. Proceedings of the 21st Americas Conference on Information Systems, San Juan, Puerto Rico.

Wang, W. (2017). Mindfulness education in information systems analysis and design, Academy of Management Proceeding, Atlanta, GA. 


\section{APPENDIX A}

\section{THE MINDFULNESS ATTENTION AWARENESS SCALE (MAAS)}

\section{Day-to-Day Experiences}

Instructions: Below is a collection of statements about your everyday experience. Using the 1-6 scale below, please indicate how frequently or infrequently you currently have each experience. Please answer according to what really reflects your experience rather than what you think your experience should be. Please treat each item separately from every other item.

$\begin{array}{cccccc}1 & 2 & 3 & 4 & 5 & 6 \\ \text { Almost } & \text { Very } & \text { Somewhat } & \text { Somewhat } & \text { Very } & \text { Almost } \\ \text { Always } & \text { Frequently } & \text { Frequently } & \text { Infrequently } & \text { Infrequently } & \text { Never }\end{array}$

I could be experiencing some emotion and not be conscious of it until some time later.

$\begin{array}{llllll}1 & 2 & 3 & 4 & 5 & 6 \\ 1 & 2 & 3 & 4 & 5 & 6\end{array}$

I break or spill things because of carelessness, not paying attention, or thinking of something else.

I find it difficult to stay focused on what's happening in the $\begin{array}{llllll}\text { present. } 1 & 2 & 3 & 4 & 5 & 6\end{array}$

I tend to walk quickly to get where I'm going without paying attention to what I experience along the way.

$\begin{array}{llllll}1 & 2 & 3 & 4 & 5 & 6 \\ 1 & 2 & 3 & 4 & 5 & 6 \\ 1 & 2 & 3 & 4 & 5 & 6 \\ 1 & 2 & 3 & 4 & 5 & 6 \\ 1 & 2 & 3 & 4 & 5 & 6 \\ 1 & 2 & 3 & 4 & 5 & 6 \\ & & & & & \\ 1 & 2 & 3 & 4 & 5 & 6 \\ & & & & & \\ 1 & 2 & 3 & 4 & 5 & 6\end{array}$

I find myself listening to someone with one ear, doing something else at the same time. 
Issues in Information Systems

Volume 18, Issue 4, pp. 105-115, 2017

\begin{tabular}{|c|c|c|c|c|c|c|c|c|c|}
\hline $\begin{array}{c}1 \\
\text { Almost } \\
\text { Always }\end{array}$ & $\begin{array}{c}2 \\
\text { Very } \\
\text { Frequently }\end{array}$ & $\begin{array}{c}3 \\
\text { Somewhat } \\
\text { Frequently }\end{array}$ & $\begin{array}{c}4 \\
\text { Somewhat } \\
\text { Infrequently }\end{array}$ & & $\begin{array}{r}\mathrm{V} \\
\text { freq }\end{array}$ & ently & & & $\begin{array}{l}6 \\
\text { most } \\
\text { ever }\end{array}$ \\
\hline $\begin{array}{l}\text { I drive places } \\
\text { there. }\end{array}$ & atic pilot' ar & wonder why & & 1 & 2 & 3 & 4 & 5 & 6 \\
\hline I find myself $\mathrm{p}$ & ied with the f & or the past. & & 1 & 2 & 3 & 4 & 5 & 6 \\
\hline I find myself $\mathrm{c}$ & ags without $\mathrm{p}$ & attention. & & 1 & 2 & 3 & 4 & 5 & 6 \\
\hline I snack withou & ware that I'm & & & 1 & 2 & 3 & 4 & 5 & 6 \\
\hline
\end{tabular}

